\title{
Bisalbuminémia: Uma Variante Rara da Albumina
}

\author{
Bisalbuminemia: A Rare Variant of Albumin
}

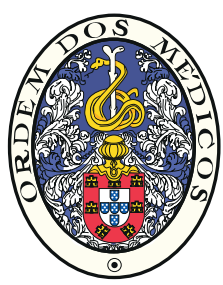

Carla GARCEZ $₫ 1$, Susana CARVALHO ${ }^{1}$

Acta Med Port 2017 Apr;30(4):330-333 - https://doi.org/10.20344/amp.7187

RESUMO

Introdução: A bisalbuminémia é uma alteração qualitativa da albumina e define-se pela coexistência no mesmo indivíduo de dois tipos de albumina sérica com mobilidade eletroforética diferente. Existem duas formas: hereditária e permanente ou adquirida e transitória. Caso Clínico: Adolescente, sexo feminino, 17 anos, referenciada à consulta hospitalar por achado incidental de bisalbuminémia detetada na eletroforese de proteínas plasmáticas, realizada em contexto de noção de diminuição da força dos membros inferiores. O exame objetivo não apresentava alterações. Foi excluída causa secundária de bisalbuminémia. Posteriormente, confirmou-se a mesma alteração em eletroforese de proteínas plasmáticas realizada ao irmão de 14 anos e à mãe.

Discussão: Descrevemos um caso raro de bisalbuminémia hereditária numa família portuguesa. Em geral não apresenta significado patológico, no entanto tem interesse para o clínico o conhecimento desta alteração analítica para melhor orientar e esclarecer os seus doentes.

Palavras-chave: Albumina; Alterações Proteínas Sanguíneas

\section{ABSTRACT}

Introduction: Bisalbuminemia is a qualitative disorder of albumin and it is defined by the coexistence in the same individual of two types of serum albumin with different electrophoretic mobility. There are two forms: hereditary and permanent, or acquired and transient. Case Report: Girl, 17-years-old, referenced to the hospital consult after incidental finding of bisalbuminemia detected in plasma protein electrophoresis performed within the investigation of diminished muscular tone in the lower limbs. Physical examination was normal. Secondary causes of bisalbuminemia were excluded. Later, it was confirmed the same disorder in plasma protein electrophoresis performed to her 14-years-old brother and mother.

Discussion: We describe a rare case of hereditary bisalbuminemia in a portuguese family. In general, this condition shows no pathological significance, however it is of interest to the clinicians the knowledge of this analytic change for better orientation of their patients.

Keywords: Albumins; Blood Protein Disorders

\section{INTRODUÇÃO}

A albumina é a principal proteína do compartimento circulatório do organismo e desempenha um papel fundamental na manutenção da pressão oncótica intravascular e no transporte de muitas substâncias endógenas e exógenas. A sua concentração plasmática pode variar de acordo com numerosas alterações fisiológicas ou patológicas. ${ }^{1,2} \mathrm{O}$ termo disalbuminémia engloba as alterações quantitativas e qualitativas da albumina. As disalbuminémias quantitativas abrangem a hipoalbuminémia, a hiperalbuminémia e a analbuminémia congénita, e as disalbuminémias qualitativas referem-se essencialmente às bisalbuminémias. ${ }^{1-4}$

A bisalbuminémia constitui uma variação qualitativa da albumina e define-se pela coexistência no mesmo indivíduo de dois tipos de albumina sérica com mobilidade eletroforética diferente em $\mathrm{pH}$ alcalino, o que traduz a presença de uma albumina plasmática normal e de uma albumina plasmática modificada. ${ }^{1-5} \mathrm{~A}$ forma modificada pode apresentar migração mais anodínica (tipo rápido) ou mais catiónica (tipo lento), de acordo com a variação do seu ponto isoelétrico. Esta alteração pode ter diversas etiologias. Existem duas formas de bisalbuminémia: hereditária (permanente) e adquirida (transitória). ${ }^{1-4,6}$

\section{CASO CLÍNICO}

Adolescente, sexo feminino, 17 anos enviada à consulta hospitalar de Pediatria/Adolescentes pelo seu médico assistente por apresentar uma bisalbuminémia na eletroforese de proteínas plasmáticas, realizada em investigação analítica em contexto de noção de diminuição de força nos membros inferiores. Não apresentava outras queixas associadas e o exame físico era normal. Não estava sob qualquer terapêutica. Foi repetida eletroforese de proteínas plasmáticas, na qual se confirmou a presença de um pico de albumina bífido, que representa a separação dos dois tipos de albumina com mobilidade eletroforética diferente, sem outras alterações (Fig. 1A). A concentração de albumina plasmática era normal.

Para excluir entidades clínicas associadas a esta alteração foi realizada função renal, proteínas totais, enzimas pancreáticas, função tiroideia e ecografia abdominopélvica que não apresentaram alterações (Tabela 1). Foi seguida em consulta de Neurologia pela queixa de diminuição de força nos membros inferiores, não objetivada no exame físico, que excluiu patologia deste foro.

Dada a possibilidade de se tratar de uma situação familiar foi solicitada eletroforese de proteínas plasmáticas aos pais e irmão da adolescente, tendo-se confirmado a

1. Serviço de Pediatria. Hospital de Braga. Braga. Portugal.

$\triangle$ Autor correspondente: Carla Garcez. carla.garcez@live.com.pt

Recebido: 12 de novembro de 2015 - Aceite: 26 de outubro de 2016 | Copyright @ Ordem dos Médicos 2017 


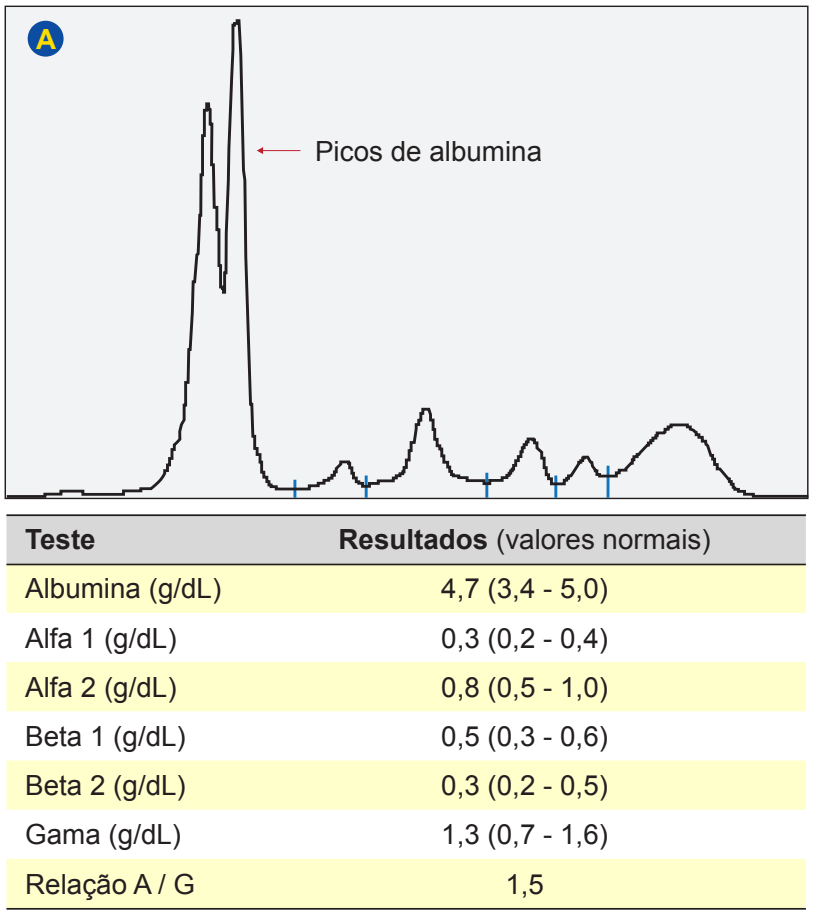

Figura 1 - Eletroforese de proteínas plasmáticas onde se observa os dois picos de albumina sérica [relativa à irmã $(A)$ e ao irmão $(B)$ ] presença de bisalbuminémia na mãe e no irmão.

O irmão, 14 anos, foi posteriormente referenciado à consulta de Pediatria/Adolescentes. Não tinha antecedentes pessoais relevantes, estava assintomático e o exame objetivo era normal. Repetiu eletroforese de proteínas plasmáticas que confirmou uma bisalbuminémia (Fig. 1B). Foi excluída causa secundária de bisalbuminémia (Tabela 1).

Os adolescentes mantêm seguimento na consulta de Pediatria/Adolescentes, sem intercorrências. Foram referenciados à consulta de Genética Médica por se tratar de

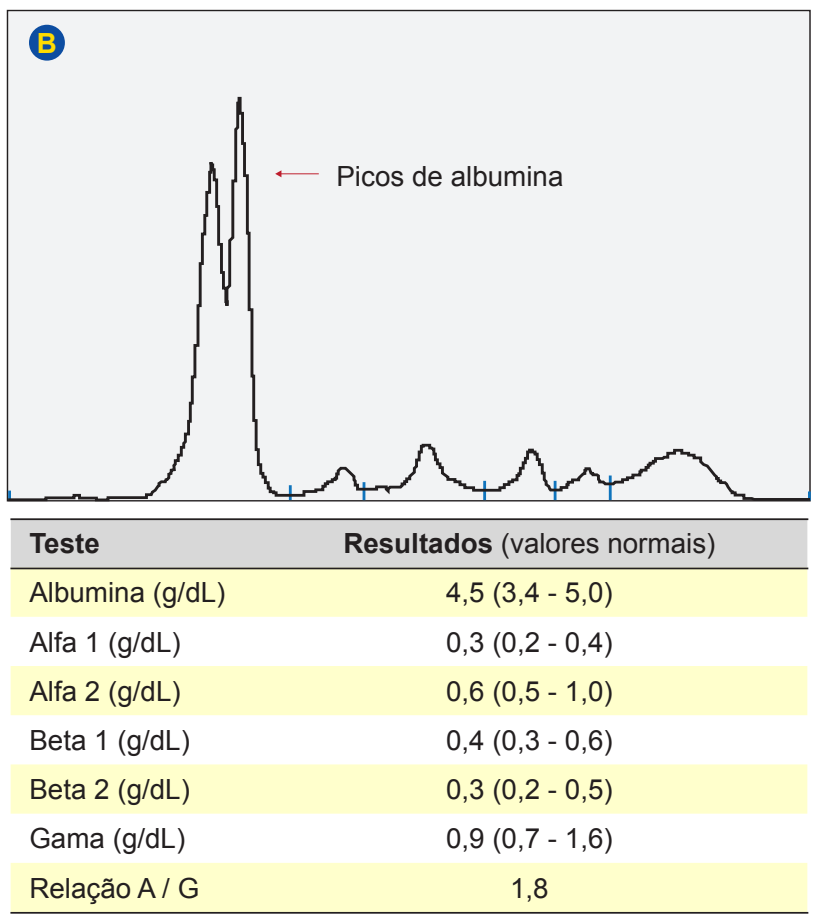

um caso de bisalbuminémia hereditária.

\section{DISCUSSÃO}

O caso apresentado descreve o achado de bisalbuminémia em três membros de uma família portuguesa. O diagnóstico foi efetuado de forma incidental, levando à necessidade de exclusão de patologias associadas e à investigação da presença da mesma alteração nos restantes familiares. Com os resultados obtidos concluímos tratar-se de um caso de bisalbuminémia hereditária.

Tabela 1 - Resultados dos exames complementares de diagnóstico realizados na consulta de Pediatria/Adolescentes

\begin{tabular}{|c|c|c|}
\hline Resultados dos exames laboratoriais e imagiológicos & Irmã & Irmão \\
\hline \multicolumn{3}{|l|}{ Soro } \\
\hline Hemoglobina $(\mathrm{g} / \mathrm{dL})$ & 12,6 & 15,8 \\
\hline Velocidade de sedimentação (mm/h) & 18 & 4 \\
\hline Ureia $(\mathrm{mg} / \mathrm{dL})$ & 34 & 44 \\
\hline Creatinina (mg/dL) & 0,7 & 0,9 \\
\hline Clearence de creatinina $\left(\mathrm{mL} / \mathrm{min} / 1,73 \mathrm{~m}^{2}\right)$ & 130 & 142 \\
\hline Sódio/Potássio/Cloro (mmol/L) & $138 / 4,2 / 102$ & $140 / 4,2 / 107$ \\
\hline Amilase/Lipase (U/L) & $46 / 133$ & $39 / 108$ \\
\hline Ácido úrico (mg/dL) & 4,0 & 4,7 \\
\hline Desidrogenase lática (U/L) & 170 & 210 \\
\hline Proteínas Totais $(\mathrm{g} / \mathrm{dL})$ & 7,8 & 7,0 \\
\hline Albumina $(\mathrm{g} / \mathrm{dL})$ & 4,3 & 4,3 \\
\hline $\mathrm{TSH}(\mathrm{uUI} / \mathrm{mL})$ & 1,180 & 3,690 \\
\hline $\mathrm{T}_{4}$ livre $(\mathrm{pg} / \mathrm{dL})$ & 1,10 & 1,03 \\
\hline $\lg \mathrm{A} / \operatorname{lgG} / \operatorname{lgM}(\mathrm{mg} / \mathrm{dL})$ & $120 / 1270 / 131$ & $132 / 1010 / 63,7$ \\
\hline \multicolumn{3}{|l|}{ Amostra de urina de 24 horas } \\
\hline Proteinúria (g/24h) & $<0,05$ & -- \\
\hline \multicolumn{3}{|l|}{ Amostra de urina pontual } \\
\hline Relação proteínas/creatinina (mg/mg) & -- & 0,058 \\
\hline Relação albumina/creatinina (mg/mg) & -- & 0,15 \\
\hline Ecografia abdominal, renal e pélvica & Sem alterações & Sem alterações \\
\hline
\end{tabular}


A bisalbuminémia hereditária é relativamente rara, de transmissão autossómica codominante ${ }^{3}$ com prevalência de 1:1000 a 1:10 000 na maior parte das populações. ${ }^{1,2,4} \mathrm{Na}$ Europa predominam as variantes de tipo lento. Foram identificadas 125 variantes de albumina. ${ }^{1}$ A alteração genética responsável é uma mutação pontual no gene da albumina humana. ${ }^{4} \mathrm{Em}$ indivíduos heterozigóticos são expressos os dois tipos de albumina, em quantidades aproximadamente iguais, o que reflete uma expressão idêntica dos dois alelos que vão controlar a biossíntese de cada metade da quantidade total de albumina. ${ }^{3} \mathrm{Em}$ alguns casos, a fração anormal da albumina pode existir em quantidade inferior. Nos homozigóticos a banda correspondente à albumina variante é exclusiva, mas a sua mobilidade é diferente, mais lenta ou mais rápida do que a da albumina normal. ${ }^{1,2,4}$ Nos casos apresentados são expressos dois tipos de albumina com mobilidade eletroforética diferente, pelo que a alteração genética está provavelmente presente em heterozigotia. A eletroforese de proteínas plasmáticas foi realizada por método capilar, técnica que não permite identificar com rigor qual dos picos de albumina corresponde à albumina normal e modificada, o que indicaria se se trata de uma variante de tipo rápido ou lento. No entanto, esta distinção não apresenta relevância clínica. A família aguarda para avaliar a necessidade de realizar estudo genético, todavia sem implicações na orientação clínica.

A bisalbuminémia hereditária é geralmente detetada incidentalmente, conduzindo ao estudo posterior dos restantes membros da família, ${ }^{1,4,7}$ como se verificou no caso apresentado. Em geral, não tem significado patológico, no entanto algumas variantes da albumina têm afinidade alterada para algumas hormonas, iões metálicos, ácidos gordos e fármacos, o que pode interferir nas suas concentrações plasmáticas. ${ }^{1,4}$ Uma alteração com significado clínico é a hipertiroxinemia bisalbuminémica familiar, uma patologia hereditária caraterizada pela presença de uma albumina sérica anormal com afinidade preferencial para a tiroxina, verificando-se valores séricos elevados de tiroxina total e livre, com níveis normais de thyroid-stimulating hormone (TSH), em doentes clinicamente eutiróideus. ${ }^{8}$

A bisalbuminémia adquirida resulta de alterações estruturais numa porção da albumina circulante, por adição ou subtração de material. ${ }^{1}$ Tem sido descrita associada a três causas principais: iatrogenia medicamentosa, como após exposição a doses elevadas de antibióticos beta-lactâmicos, pela ligação à albumina de antibióticos com um anel beta-lactâmico; na pancreatite aguda, especialmente se complicada por fístula ou pela rotura de pseudocistos, pela proteólise limitada da albumina pelas enzimas pancreáticas; e em situações como o mieloma múltiplo, pela ligação à albumina de certas imunoglobulinas monoclonais. Foram ainda descritos casos raros de bisalbuminémia transitória em indivíduos adultos com síndrome nefrótico, insuficiência renal crónica e diabetes mellitus, mas o mecanismo fisiopatológico que possa explicar esta associação não está esclarecido. ${ }^{1,9-14}$ A deteção de uma bisalbuminémia adquirida poderá apontar um processo patológico subjacente, fornecendo ao clínico uma pista para um possível diagnóstico.

Descrevemos um caso raro e benigno de bisalbuminémia permanente e hereditária, numa família portuguesa, atendendo à exclusão das restantes causas. Apesar de não parecer haver implicações clínicas para esta alteração qualitativa da albumina, tem interesse para o médico o conhecimento desta alteração analítica, para que possa esclarecer e orientar os seus doentes. Por outro lado, a determinação e investigação destas variantes genéticas da albumina, ao estudar a sua estrutura tridimensional, locais de ligação, propriedades enzimáticas e estabilidade, poderá ter interesse terapêutico futuro, nomeadamente no desenvolvimento de novos fármacos com mecanismos de transporte e atuação mais específicos.

\section{PROTECÇÃO DE PESSOAS E ANIMAIS}

Os autores declaram que os procedimentos seguidos estavam de acordo com a Declaração de Helsínquia da Associação Médica Mundial.

\section{CONFIDENCIALIDADE DOS DADOS}

Os autores declaram ter seguido os protocolos do seu centro de trabalho acerca da publicação de dados.

\section{CONFLITOS DE INTERESSE}

Os autores declaram não terem qualquer conflito de interesse relativamente ao presente artigo.

\section{FONTES DE FINANCIAMENTO}

Os autores declaram que não houve contribuição de títulos ou bolsas para a realização deste trabalho.

\section{REFERÊNCIAS}

1. Bach-Ngohou K, Schmitt S, Le Carrer D, Masson D, Denis M. Les dysalbuminémies. Ann Biol Clin. 2005;63:127-34.

2. Kragh-Hansen U, Minchiotti L, Galliano M, Peters T. Human serum albumin isoforms: genetic and molecular aspects and functional consequences. Biochim Biophys Acta. 2013;1830:5405-17.

3. Ouzzif $Z$, Derouiche $M$. Bisalbuminémie héréditaire chez un patient diabétique et hypertendu. Ann Biol Clin. 2002;60:707-10.

4. Kurnit DM, Philipp BW, Bruns GA. Confirmation of the mapping assignment of human serum albumin to chromosome 4 using a cloned human albumin gene. Cytogenet Cell Genet. 1982;34:282-88.

5. Leahy DT, McLaughlin H. Four cases of fast-type bisalbuminemia in an irish population. Clin Chim Acta. 1980;104:181-6.

6. Dodig S, Čepelak I, Benko B, Raos M, Branović K. Bisalbuminemia in two croatian families. Arch Med Res. 2000;31:608-12.

7. Bellomo A, Mancinella M, Troisi G, Marigliano V. A rare familiar case of hereditary bisalbuminemia and diabetic predisposition: a possible predictive link? Arch Gerontol Geriatr. 2010;50:345-6.

8. AvRuskin TW, Juan CS, Weiss RE. Familial dysalbuminemic hyperthyroxinemia: a rare example of albumin polymorphism and its rapid molecular diagnosis. J Pediatr Endocrinol Metab. 2002;15:801-7.

9. Akhmouch I, Alayoud A, Bahadi A, Zajjari Y, Montasser D, El Allam M, et al. Bisalbuminemia during remission of nephrotic syndrome. Saudi $J$ Kidney Dis Transpl. 2012;23:1251-3.

10. Kalambokis G, Kitsanou M, Kalogera C, Kolios G, Seferiadis K, Tsianos 
E. Inherited bisalbuminemia with benign monoclonal gammopathy detected by capillary but not agarose gel electrophoresis. Clin Chem. 2002;48:2076-7.

11. Srikrishna G, Mathai D, Abraham OC, Kaur A, Kanagasabapathy AS, Pulimood BM. IgG multiple myeloma and alloalbuminemia: as unusual association. J Assoc Physicians India. 1994;42:331-2.

12. Ejaz AA, Krishna M, Wasiluk A, Knight JD. Bisalbuminemia in chronic kidney disease. Clin Exp Nephrol. 2004;8:270-3.

13. Ahmad J, Khan AS, Siddiqui MA, Tewari SG, Khan RU. Bisalbuminemia in nephrotic syndrome (a case report). Jpn J Med. 1984;23:45-7.

14. Hoang MP, Baskin LB, Wians FH. Bisalbuminuria in an adult with bisalbuminemia and nephrotic syndrome. Clin Chim Acta. 1999;284:1017.

\section{INTRODUCTION}

